\title{
Place, Body and Nature: Rethinking Japanese Sense of Fudo and Minamata Disease
}

\author{
KUMAGAI Keichi \\ Department of Geography and Environmental Studies, Ochanomizu University; Tokyo 112-8610, Japan. \\ E-mail: kumagai.keichi@ocha.ac.jp
}

Received November 10, 2015; Accepted November 18, 2016

\begin{abstract}
The idea of place has been a common concern in human geography including among feminist geographers since the 1970s. While the question of place in Western cities has been critically discussed, place or placemaking and displacement in the non-Western world have not been well developed. The author addresses the issue in terms of the idea of ' $f u d o$ ' (milieu) which has been subject to particular attention in Japanese philosophy and geography since the 1930s, owing to popularization by Tetsuro Watsuji and Augustin Berque. In this paper, the author highlights the ideas of fudo through illustration of a grave historical case of suffering in Japan: Minamata Disease. Minamata Disease, caused by the consumption of fish contaminated by methyl mercury, emerged in the 1950s. This tragedy can be understood as the outcome of three scales of fudo relationship: 1) the interrelationship between the local marine ecosystem and fishers' practice on the sea; 2) political and economic domination of Minamata city by the Chisso company; and 3) national sentiment and the human-environment relationship in Japan at the time. I highlight the narratives of two women in Minamata, Michiko Ishimure and Eiko Sugimoto, as cases that embody the local fudo relationship. Their narratives present essential interactions in Minamata between the sea, land, deities, embodied lives and survival, which collectively construct fudo. Simultaneously, these narratives illustrate Minamata, a place that now attracts people from elsewhere interested in curing their minds and bodies. By connecting divided localities, the local people's movement reconstructed the fudo in Minamata that was once destroyed.
\end{abstract}

Key words place, body, nature, fudo, Minamata Disease

\section{Introduction}

It is popularly believed that Japanese culture views nature as possessing a sublime value. While Western or Judeo-Christian culture is said to center on humans in a way that props up belief in their control over nature, Japanese culture appreciates "natural-ness" in its formative arts such as architecture or gardening. Japanese culture tends to merge with nature, rather than foster a dichotomy between nature and culture (e.g. Terada 1935; Nomoto 2006; Ueda 2012). Such statements, if understood not just as stereotypes and not at a superficial level, provide an opportunity for reflection on the sense of place in terms of Japanese geographical thought and may allow us to situate the relationship between humans, sentiment and materiality. However, such a reflection must be taken on with care so as to avoid falling into essentialist views of Japanese culture as static and uniform, determined by masculine taste.

In this paper, I examine and reconstruct the Japanese concept of fudo (milieu), the relationship between nature and culture, from a local and gender perspective. For this aim, I will discuss the following three points. First, I will briefly review the concept of place in geography together with the feminist critiques. Second, I will examine the concept of fudo in Japanese geographical thought, focusing on Watsuji $(1963)$ and Berque $(1985,1988)$ and reveal its potentiality to consider the relationship between human and non-human, nature and culture as well as its limitation. Third, I will highlight a historical case of Japanese strife and suffering, Minamata Disease, which gained public attention from the late 1950s (Ishimure 1969, 1974, 1976, 2006; Harada 1972, 1985; Miyamoto 1977; Irokawa 1995a, 1995b; see also George 2001). This event evoked deep concern in Japan as human economic activities destroyed the natural environment along with human bodies. Then, I will scrutinize this alternative view of fudo as not static and homogenous but as a dynamic relationship between nature, body and society, together with local and gender sensitivity.

\section{Rethinking Place with Feminist Critiques}

The idea of place has occupied a position of common concern within human geography since humanistic geographers discovered and reoriented it in the early 1970s (Tuan 1974, 1977; Relph 1976). Place is significant as a location or a particular space endowed with meaning by 
humans (Cresswell 2004). This opened up a micro-level and human-centered approach to human geography (that is, making it more "human") by focusing on not only public space, often planned and controlled by men, but also private space occupied by women and men.

Feminist geographers, however, criticized humanistic geography for romanticizing place and home as a nostalgic, comfortable site for men shaped by an aesthetic masculinity, while women often recognize it as a central place of oppression (Rose 1993). Rose contends that, "[t]hus place, as the humanistic Other, remains unknowable, despite being the focus of humanistic claims to knowledge" (Rose 1993: 61). While feminist geographers have criticized the masculine conceptualization of place, they simultaneously sought to reconstruct the concept of place opposing a universal knowledge from above (Massey 1991). Feminist academics, including geographers, accentuate that discussions from nowhere are perilous. Instead, they highlight "situated" knowledge (Haraway 1991) from somewhere.

In the discourse of human geography, at least three aspects of "place" have been foregrounded (Onjo 1998); 1) place as a private space or intimate sphere that generates a sense of security or belonging (Tuan 1974), 2) place as a socially and economically constructed built environment, often in a capitalist context (Harvey 1989, 1993), and 3) place as a potential site of resistance against the capitalist production of space; that is a lived or representational space (see Lefebvre 1974). As noted earlier, the first aspect was criticized by feminists as well as Marxists and social constructionists (Harvey 1989; Massey 1993). ${ }^{1}$ Nevertheless, such a view of "place" is not insignificant, particularly in light of massive dis-place-ment of people generated in a globalizing world. I believe all three aspects are contradictory at one level but intersect and remain interrelated, especially as pertains to place in the lives of displaced persons throughout the global South and global North.

Massey is one of the leading discussants on place, providing the idea of a "global sense of place" (Massey 1993). Lately, Massey (2005: 140) states, "what is special about place is precisely that throwntogetherness, the unavoidable challenge of negotiating a here-and-now; and a negotiating which mast take place within and between both human and nonhuman." Massey is also sensitive to the sizeable disparities emerging in a globalizing world. She stresses a common "responsibility" for listening to the voices of others over social and spatial distances (Massey 2005: 68). Contrary to popular views in the global North that present Northern nations and cultures as under inva- sion by immigrants from the South, Massey communicates that "the margins have not arrived at the center" (Massey 2005: 88).

Concerning the view of marginalized peoples in the Global South, Escobar, a cultural anthropologist and critic of development discourse (Escobar 1995), brings attention to the third aspect of place. Escobar (2008) presents resistance to violent capitalist development by black (African Colombian) inhabitants of the Colombian Pacific using terms of 'place,' 'region' and 'territory.' African Columbian and indigenous people utilize their local knowledge of their 'place' and eco-system in the region as they collaborate with NGOs and develop strategies of resistance. This essentially amounts to a reconstruction and reassertion of 'place'; the formation of the Pacific as a region-territory has been innovated by a political project that may be considered a subaltern strategy of localization (Escobar 2008: 59). Here, the first and the third aspects of place are entangled and critically represented. ${ }^{2}$

It is crucial that we recognize place and place-making as well as displacement in a globalizing world, and particularly that we do so together with gender sensitivity to examine the real potential for resistance in localities of the global South and global North, as well as those of the Western and non-Western worlds. For the sake of adequately grasping such dynamic processes, I believe that the conceptualization of place should be explored through extended recognition of negotiations that occur among human and non-human actors, while remaining sensitive to gender, by including culture and nature as well as subjectivity, materiality and body.

While humanistic geographers paid some attention to body (Tuan 1974, 1977), the human body had not been well-discussed in human geography until feminist geographers reclaimed its significance in the 1990s (Simonsen 2009). Longhurst, in her book titled "Body," recognized material bodies as a way of understanding the relationship between people and places. She stated that although both men and women have bodies, "men are widely considered to be able to seek and speak universal knowledge, unencumbered by the limitations of the material body placed in a particular material context whereas women are thought to be bound to the desires of their fleshy, 'natural' bodies placed in time and space" (Longhurst 2001: 13). She scrutinized how pregnant women feel themselves as being trespassing or out of place in public space. Longhurst pointed out that in Western culture, while white men may have presumed that they could transcend their embodiment by seeing the body as little more than 
a container for the pure consciousness it held inside, this was not allowed for women, blacks, homosexuals, or people with disabilities (Longhurst 2001: 13).

The dichotomy between mind and body, culture and nature, allocating the former to the masculine and the latter to the feminine, is deeply rooted in Western thought (Merchant 1980). If such masculine separation has Eurocentric characteristics, it is crucial to reassert the vital role of body and nature in place-making or displacement, instead of excluding them as others. I believe that a re-examination of the historical suffering of Minamata Disease in Japan through a fudo (milieu) perspective should contribute to achieving this aim.

\section{The Concept of Fudo in Japan}

Discussions of fudo have become a subject of special attention within Japanese philosophy and geography since the 1930s. The word fudo, which originates from the Chinese language, consists of $f u$ meaning "wind" (also read as kaze) and do meaning "ground" or "soil" (also read as tsuchi). The idea of fudo became popular in Japan through the work of Tetsuro Watsuji (1963), a philosopher and scholar of ethics. The idea was recently reconstructed by Augustin Berque (1988), a French geographer and Japanologist. ${ }^{3}$

\section{Watsuji Tetsuro and his discussion of "fudo"}

Watsuji published Fudo: Ningengaku-teki Kosatsu (Milieu: Consideration from human studies) in 1935. In this influential book, Watsuji examined fudo as a structural moment for human existence. In his definition, fudo is a complex unity of a particular area's climate, weather, geology, soil, terrain, and landscape. Furthermore, it is not just "nature" alone, but an interactive relationship between nature and human beings-as both individuals and a collective. ${ }^{4}$ Watsuji emphasizes that fudo defines a moment for individuals to understand and identify themselves, as well as a setting for communal understanding or group-identification, shaping a way of life in relation to a milieu. Watsuji classified three prototypes of fudo, consisting of "monsoon" (South and East Asia including Japan), "desert" (mainly West Asia or Middle East) and "meadow" (Europe).

Although Watsuji's conception of fudo is appealing and has been very popular in Japan, it has some serious shortcomings. Watsujis typology of three different types of fudo (with the exception of only Japan) was inspired by his physical experiences traveling through landscapes during a voyage to Europe on his way to study in Germany in 1927-1928. Thus, the description of each typology was shaped by substantial environmental determinism. He emphasized spatial perspectives that opposed historicism or Marxism which were dominant in the thought of Japan at the time. Ironically, his work reflects shortsightedness in terms of historical perspectives. ${ }^{5}$

Watsuji described the Japanese national mentality as comprised of "shimeyakana gekijou to sentoteki tentan" (Watsuji 1963: 166) or a duality of a "sudden uprising of emotion hidden in the mind along with sudden feelings of resignation after a fierce fight," which relates to the changeable Japanese climate, seasons, and natural environment (from tropical summers to snowy winters). He presents this quality within Japanese-ness as wholly embodied in the 'ie, meaning family (as in succeeding generations of extended family over time), home, and house all at the same time. His analogy of ie ultimately extends to Japan as a nation and a state or 'kokka', with its emperor positioned as the father. He stressed that solidarity is a distinguishing feature of Japan manifested in a whole-hearted and bodily dedication to ie and kokka. This, however, has not been an everlasting sentiment of Japanese culture but a norm compulsorily forced onto all Japanese citizens prior to and during the Second World War.

Watsuji's idea of fudo was deeply influenced by Heidegger's idea of 'existence.' In order to clarify the temporal and spatial structure of human existence, he presented the idea of space, or fudo, which he claimed had been neglected relative to time. Against Marx's idea of historical materialism, popular in Japanese academia at the time, he tended to look upon fudo as an essentialized and static component rather than one historically constructed, thereby neglecting the changing relationship of human society to nature. Watsuji only discussed fudo as existing at the macro level and on a broader regional scale when considering Europe or Monsoon Asia and on a national scale for China and Japan, while insisting on the inseparability between mind and body.

\section{Augustin Berque and reconsideration of fudo in Japan}

Augustin Berque, a French geographer and Japanologist, develops the idea of fudo by critically examining Watsuji's idea. Berque, based on his own understanding of Japanese culture and geography, situates fudo as a traject/trajectivitet between culture and nature. He stresses that the idea should transcend dichotomiessuch as between culture and nature, objective and subjective, or reason and sensibility-and reconstructs human geography as a whole into a mesologie or a study 
of milieu.

Berque defined fudo as the relationship a society holds with space and nature (Berque 1988: 129). He states that fudo is both physical and artificial, as well as material and ideal, wherein all elements are inseparable because neither culture nor society can exist without connection to place and space. Together, these comprise fudo.

Berque highlights distinguishing characteristics within Japanese culture using a sophisticated coding of the relationship between culture and nature as constructed over the extended course of history. For example, an enormous number of kigo, or "words to express season," in Japanese haiku reflect a Japanese sensibility towards climate and seasonal change. He claims that it is not seasonal change itself but such codes, shared even among ordinary persons, that gives the Japanese people a more subtle sense of the effects of climate and nature (Berque 1988: 15-23). ${ }^{6}$

Berque's discussion stimulates new consciousness of Japanese geography in particular as well as the potentiality of geographical thought in general. While Berque opposes environmental determinism intimating that Japanese people are sensitive to nature because nature is changeful in Japan, he does not fall into mere theory of representation. The distinguishing features of Japanese culture, as they relate to nature, are based on physical environment or a materiality that continuously "irrigates" Japanese people's sentiments as well as their culture. This is the mesologie or the theory of milieu in his terms, which is equivalent to an alternative geography he advocates (Berque 1988: 129-180).

Berque highlights the fudo relationship in Japan as a model capable of transcending Western dichotomies, such as those between subject and object, culture and nature, or ideal and material. He, however, is not only sympathetic with Japanese culture but also relatively critical of it. In his book he raises the issue of environmental destruction throughout Japan during the era of high economic growth in the 1950s and 1960s. He states that the destruction seems contradictory due to the way in which Japan's economic exploitation of the environment spoils the very nature that society has developed such a sophisticated appreciation for.

However, Berque argues that there is no contradiction. Instead, the seemingly conflicting outcomes share a common origin within Japanese sensibility and logic derived from their fudo. Shizen, the Japanese word for "nature", is inclusive of both nature external to people and human nature manifest internally. Japanese cultural norms encourage people to pursue chowa or harmony as an ideal in relationships with nature as well as each other.
Within chowa, human agents or subjects do not seek to stand independently but rather in a state of subjectivity that melds their existence into the archetype of nature. The word "shizen" consists of two characters: one read as onozukara (meaning "spontaneous") and one read as nari (meaning "to generate"), which together suggest something "spontaneously generating" or proceeding. If things are considered to be "spontaneously proceeding," then individual people would have no power to oppose or stop them (because to do so would be "unnatural") (Berque 1988: 231-243). Thus, Berque intimates, economic development was "natural" in this sense in Japan.

\section{Reconsidering fudo perspective and Minamata Disease}

In the following discussion examining Minamata Disease and fudo in Minamata, I present an alternative idea of fudo. Watsuji, as well as Berque, only discuss Japanese fudo at the national level and not at the local. Fudo in Japan, however, is not homogenous but of diverse and dynamic forms. Fudo could be discussed in different scales: at transnational, national, regional and local levels. Fudo should not only be understood by nation, but rather as a more concrete, locally-based relationship or inclination between humans, society, culture and nature. I define fudo as the esteemed inclination inherent to relationships between nature and culture, person and society, mind and body, and human and non-human, all rooted in a particular place. It lasts over time, not changing swiftly, but also not unchangeable; rather, it is dynamic and historically constructed.

We should also remain aware that different local fudo relationships are continuously contested and a particular fudo may be forcibly distinguished against the will of the local people, as was the case of fishers' fudo in Minamata. Minamata Disease is a fierce suffering, or destruction of the human body, caused by methyl mercury released into the Shiranui sea by Chisso Company and ingested through fish. Primary victims were fishers because of their intense and intimate relationship with fish and the sea in body and mind. Fishers, however, were criticized and oppressed by other Minamata citizens because they-recognized as outsiders in the Minamata regionwere believed to have spoiled the fame of Minamata by their words and actions against the economically- and politically-dominant Chisso Corporation. Therefore, Minamata Disease was itself an issue rooted in the entangled relationship between body, nature and society, which together comprise the fudo perspective. 


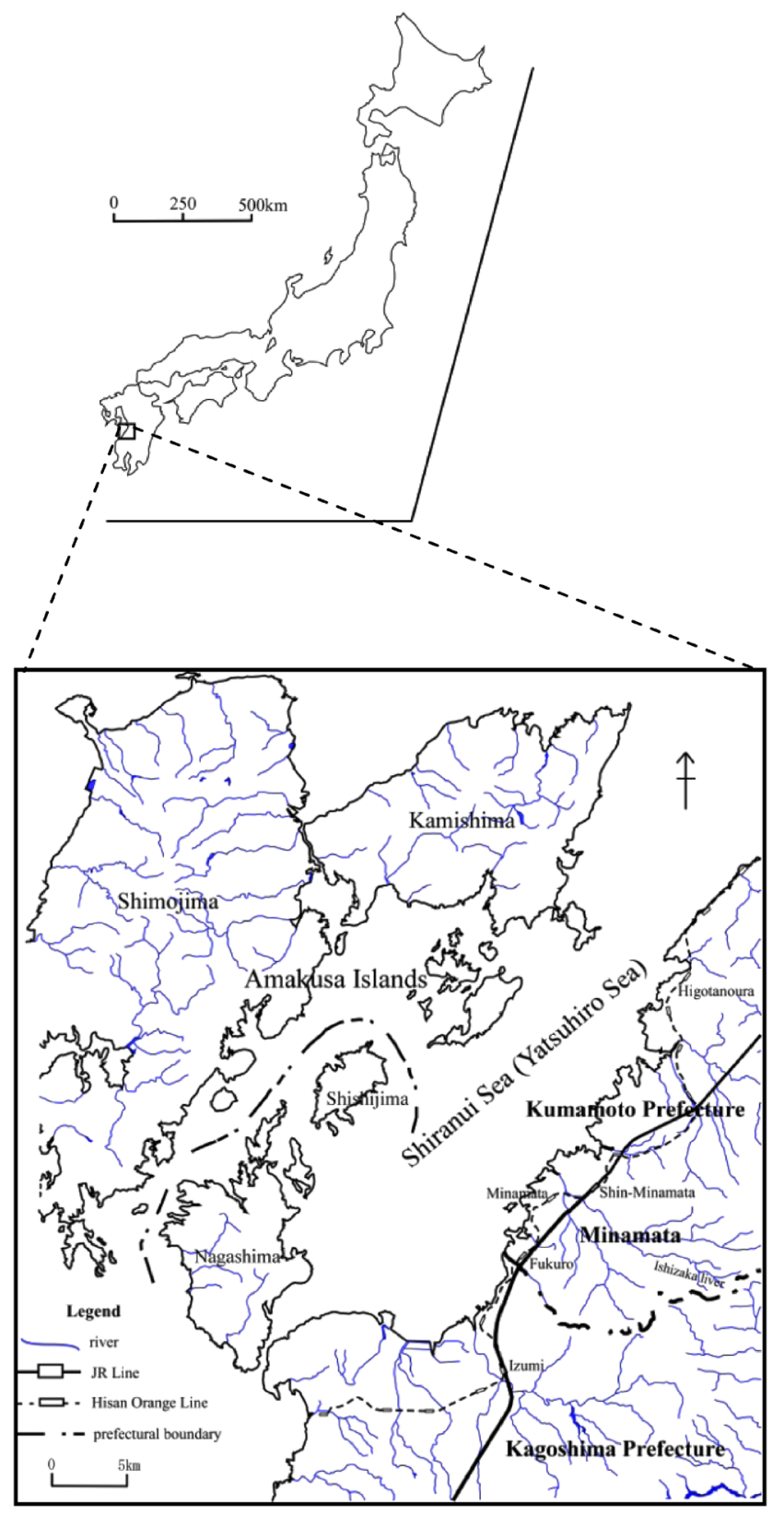

Figure 1. Minamata and the Surrounding Area.

Elaborated by Yukari Nakadai based on a national base map "Yatsushiro" at a scale of 1:50,000 issued by Geospatial Information Authority in Japan.

\section{Minamata Disease and Fudo in Minamata}

\section{The background of Minamata Disease}

Minamata is a small town located in Kumamoto prefecture in Kyushu, a southern part of Japan. The township faces the Shiranui Sea, which is surrounded by the Amakusa islands and appears almost like an inland sea (Figure 1). The Shiranui Sea is rich for fishing and, for this reason, many fishing villages are situated around the coast.

Minamata is a typical Japanese kigyo-joka machi, (lit. a firm's castle town or a town that is economically, socially and politically dominated by one particular firm), in this case, the Chisso corporation. Chisso was established in Minamata in 1907, when the city was an unpopulated village (Table 1). Chisso primarily produced chemical fertilizers using carbide. Over the years, Chisso's production grew dramatically and the company expanded into building factories and hydropower dams as far as Korea, which was a Japanese colony at the time. Chisso's economic activity and expansion was bolstered by Japan's colonial policy and the company reaped great profit.

In the 1930s, Chisso started to produce acetaldehyde, mainly for production of PVC (polyvinyl chloride). Methyl mercury served as the catalyst for production, and was directly dumped into the sea without being treated properly. Methyl mercury contaminated plankton and small fish, and processes of bioaccumulation led to its concentration in bigger fish. Early on, the first victims of acute mercury poisoning from the sea were crows and cats who suffered and died while exhibiting symptoms that resembled madness. Human beings were next.

The first human victims were officially found in 1956. Humans appeared to suffer the same symptoms as animals, which included involuntary bodily convulsions, and many people died within a short span of time. Film images of patients suffering from uncontrollable full-body convulsions sent shock waves through Japan at the time. However, Chisso did not admit to mercury being the real cause, or to their responsibility, until 1968 and continued to dump fluid waste into the sea, increasing the number of victims. Most sufferers belonged to a community of fishers, to whom fish comprised not only their livelihood but also their diet. Most victims in Minamata were chronic patients who endured long-term suffering. The exact number of persons who suffered from Minamata Disease is still not known today. Although a wide variety of symptoms may be caused by mercury poisoning, only people suffering specific ailments were formally recognized as victims by an official committee for Minamata Disease. The official count is roughly 12,600 people, but a massive number of sufferers have remained unrecognized for decades, some of whom have gone to court for recognition and struggled in the legal system for years. Therefore, suffering caused by Minamata Disease did not at any point cease but still continues today. ${ }^{7}$

There are several reasons why Minamata Disease is closely related to local, regional and national scale fudo relationships between society and nature.

First, it occurred particular to local marine ecosystems and relationships between people and nature by the Shiranui Sea. The locality includes a quiet, untroubled and shallow sea (only $15 \mathrm{~m}$ in depth, at its deepest) sur- 
Table 1. Chronology of major events concerning Minamata Disease

\begin{tabular}{|c|c|}
\hline Year & Event \\
\hline 1908 & $\begin{array}{l}\text { Nippon Chisso Hiryo (Japan Nitrogen Fertilizer) Co. is established in Minamata; Known as Nitchitsu (Later renamed Shin-Nitchitsu Co. in } 1950, \\
\text { and Chisso Co. in 1965). }\end{array}$ \\
\hline 1932 & Nitchitsu begins producing acetaldehyde and releasing drainage into Minamata Bay. \\
\hline $1950 \mathrm{~s}$ & Large numbers of cats and crows manifest signs of madness and die; Human victims also emerging. \\
\hline 1956 & (May 1.) Official discovery of Minamata Disease: The first human victim is diagnosed in Shin-Nitchitsu's factory hospital \\
\hline 1959 & "The fishers' riot": Minamata fishers claiming compensation from Shin-Nitchitsu break into the factory. \\
\hline 1963 & A Kumamoto University research group officially announces methyl mercury as the cause of Minamata Disease. \\
\hline 1968 & Production of acetaldehyde is terminated; The Japanese government officially acknowledges methyl mercury as the disease's true cause. \\
\hline 1969 & First lawsuit against Chisso begins in Kumamoto district court. \\
\hline 1973 & $\begin{array}{l}\text { Victims of Minamata Disease win their lawsuit against Chisso: A compensation agreement is reached between Chisso and its victims providing } \\
18 \text { million yen for each death, and 16-18 million yen for each recognized patient along with free medical care. }\end{array}$ \\
\hline 1977 & Kumamoto prefectural government starts cleaning polluted sediment in Minamata Bay. \\
\hline 1978 & The Ministry of the Environment announces new criteria for patient recognition causing a rapid increase in the number of dismissals. \\
\hline 1990 & "Ecopark Minamata" opens on reclaimed land in Minamata Bay. \\
\hline 1995 & $\begin{array}{l}\text { The national government proposes a resolution for unrecognized patients: } 2.6 \text { million yen in compensation per person. Most patients accept } \\
\text { this. }\end{array}$ \\
\hline 2004 & In a lawsuit originating in the Kansai region, the Supreme Court rules that both national and prefectural governments are responsible. \\
\hline
\end{tabular}

Adapted and translated from Minamata Disease Chronological Table (Minamata-byo Ryaku-Nenpyo). In Soshisha (the Supporting Center for Minamata Disease), 2016, Retrieved May 17, 2016, from http://www.soshisha.org/jp/about_md/chronological_table.

rounded by the Amakusa islands. Therefore, the waste water from the Chisso factory did not flow out to the larger sea but, rather, accumulated within the confines of the Shiranui where it contaminated fish. Local fishers were proud of their ability to catch fish at any time and consume large amounts every day.

Second, there is a regional scale fudo relationship between residents and the Chisso company or fudo of a castle firm's town. This relationship intersects with clear social stratification in Minamata (Irokawa 1995a). The plant manager of the Chisso company exercises near absolute power, like a king, within the city. In addition, persons serving as high-ranking employees are usually university graduates from Tokyo or other major cities, although some inhabitants from Minamata and surrounding areas are also recruited and regarded as local elite. Not only is the local urban economy, inclusive of government revenue, heavily dependent on Chisso company and employee purchasing power but so too is the whole city's basic social services, such as shopping and medical services, which are provided within Chisso company facilities. The total area of Minamata city covers all of Minamata river basin, which is comprised of many different localities besides townships (such as Jinnai) including mountain villages (such as Kugino), agricultural villages (such as Susubaru) and fishing villages (such as Yudo and Modo) (Figure 2). In such a local power struc- ture, fishing people, most of whom migrated from the Amakusa islands, and their habitats of the fishing villages tended to be considered as 'outsiders' or Others. This is why persons suffering from Minamata Disease, most of whom were fishers, face serious discrimination from other residents in Minamata. The acquired ailments were rare and deeply rooted in the local environment, thus the name of the malady: Minamata Disease (Minamata-byo). The city attained a negative image due to the incident, and fishers-the "outsiders" who suffered from the disease-were blamed as the root of the spoiled fame of the city. The movement formed by people with Minamata Disease seeking compensation from Chisso for their suffering was treated harshly and attacked, out of concern that it would ruin the company. After winning a court victory in 1973, sufferers faced serious accusations of jealousy from other Minamata citizens because of the amount of compensation they received. In this way, those struck with Minamata Disease suffered not only physically, but also socially.

Finally, it also relates to a national scale fudo, the relationship between nature and society in Japan. Japanese society in the 1960s was devoted to achieving a national goal of high economic growth through exploitation of the natural environment. As nature is perceived to exist outside of the economy, Japanese society tended to overlook environmental change or degradation as it pursued 


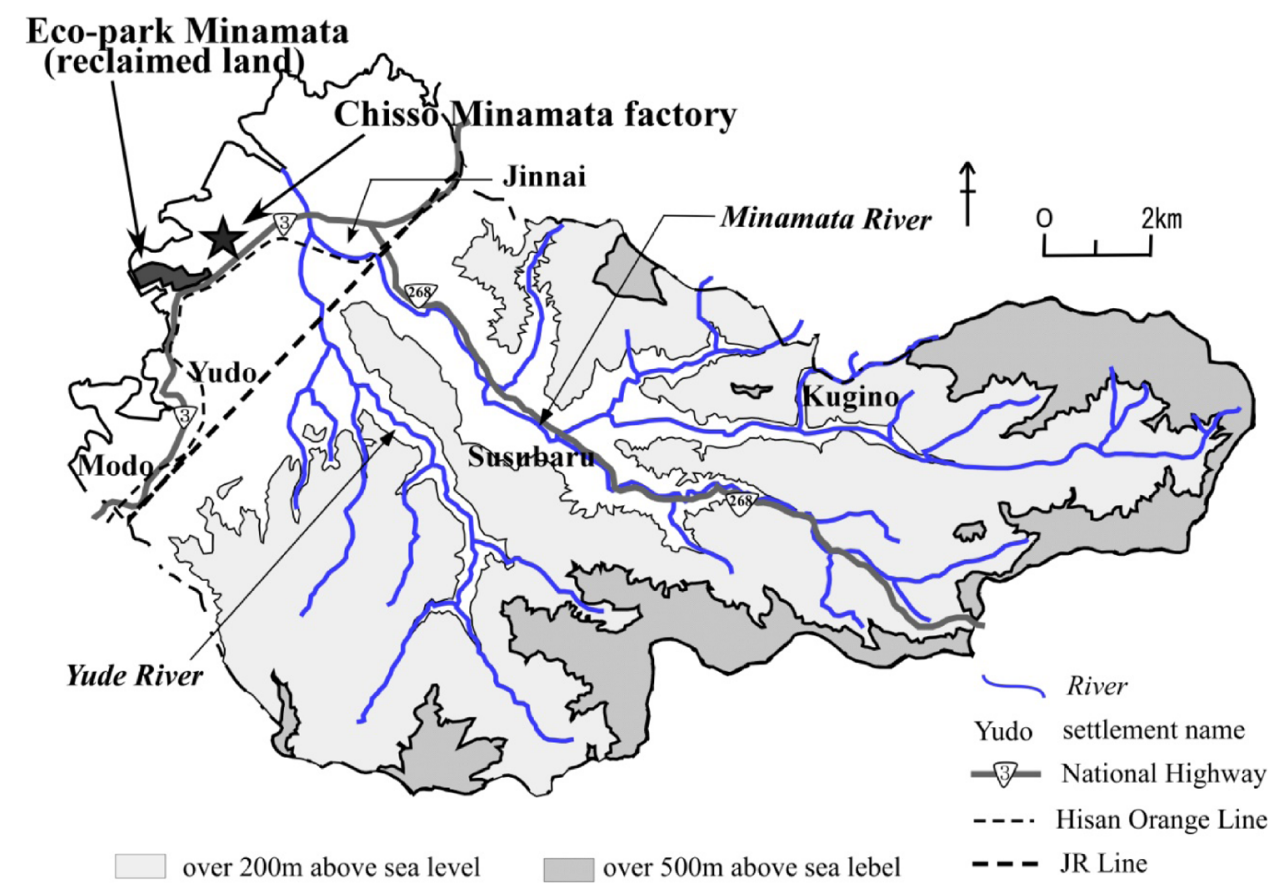

Figure 2. Minamata city.

Elaborated by Yukari Nakadai based on the Minamata Environment Learning Map in Soshisha (the Supporting Center for Minamata Disease): n.d. A Guide for Minamata Environment Learning.

economic growth. Moreover, as Berque (1988) stated, this inclination towards achieving economic growth was nearly impossible to stop as economic growth itself was viewed as part of a "natural" (self-generating) process. The Chisso-dominated municipality of Minamata, where no one could oppose the firm's economic activity, is an epitome of the dynamic interplay between economic growth and the Japanese environment at the time.

\section{Michiko Ishimure's narrative of Minamata Disease sufferers and their fudo}

Michiko Ishimure (1927-) is a distinguished story teller and chronicler of Minamata Disease. Ishimure was born and raised in Minamata town. At the age of eight, she moved to a different, marginalized neighborhood within the town owing to her grandfather's bankruptcy. In her autobiography (Ishimure 1976), she vividly tells of her sensibilities and spiritual communion with both human and the non-human things such as trees, shores, waters and airs, as well as sex workers and her mentally unstable grandmother.

Her three-volume series of books on Minamata Disease (Ishimure 1969, 1974, 2006) unreservedly reveals the tragedy of the disease through the reality of changing relations between minds and bodies, as well as the interrelationship between human and non-humans. Her first book Kugai-Jodo (Ishimure 1969) shocked Japanese society as it informed of the real tragedy of Minamata Disease and the deep suffering of patients. Livia Monnet, a trans- lator of Kugai-Jodo, described Ishimure as "a speaker who voices the suffering, anger, and unfulfilled grievances of the Minamata Disease victims and the impoverished fisherfolk in the Shiranui Sea area. She also claims to act as a medium or shaman for the resentful spirits and ghosts of those who died of the poisoning" (Monnet 1990: xiv) .

Ishimure starts her story with a description of the Yudo settlement (a fishers' village and one of the centers of Minamata Disease) and its local environment consisting of entanglements between humans and nature, such as the inlet's coast line, fishing boats, mandarin orange trees, naked children playing and elderly fishers. Then she begins to tell the story of her first encounter with a boy, who suffered from Minamata Disease, describing in detail his disabled and blind body and his lonely actions of practicing baseball with a stick and a small stone (Ishimure 1969: 6-13).

"Young Kuhei held a stick in his hands. Faltering through I know his gait and movements always were, he seemed for an instant to have petrified in that baseball posture, his back bent in an ugly curve. Seen from the back he looks like an old man... He seemed to be struggling with all his might against his own prematurely aged body. And yet his skin exuded the delicate tender smell of youth and his shoulders showed an unmistakably adolescent bold angularity. He might have grown into a robust fisherman if he had not been affected with Minamata Disease. He had old, worn 
clogs on. The simple action of putting his clogs on was a terrible trial" (Ishimure 1969: 10; translated by Monnet 1990: 7).

Local fishing persons, as she presents them, long viewed the Shiranui Sea as a fantastic place for catching fish, and even refer to it as "the sea of gushing fish" (io waku umi). "We just row into the bay out there stretching itself a few hundred steps from your house like your own garden, and find fish to our heart's content" (Ishimure 1969: 181; translated by Monnet 1990: 204). Fishers customarily ate large amounts of fish at each meal and have pride in their way of life. "Compared to the Tokyo folks we live like kings... Out on the sea it's as if the whole world belonged to you." (Ishimure 1969: 181-182; translated by Monnet 1990: 205).

Ishimure represented the misfortunes and hardships of the Minamata sufferers who express their feelings in Minamata dialect. While the disease had been originally rumored as Minamata's "fudo-byo" (local particular disease in Minamata), Ishimure's work impresses it is a disease of fudo in the truest sense.

Ishimure (2006) describes the local fudo of the Shiranui Sea in relation to her own embodied sense of sight, touch, smell, and sound, which reminds her of an ancient harmony maintained between the fishers and the sea. But this dream was suddenly interrupted by the invasion of plastic brought ashore, representing the Chisso factory and modern materialistic civilization (Ishimure 2006: 63-64). ${ }^{8}$ She continues, however, that "lately many people have been spiritually attracted to this sea and come to Minamata, although that sickness leading to death had started here" because "this sea was motherly indeed" (Ishimure 2006: 64; translated by the author).

Then she describes the local fudo of Minamata manifested in a rapport between culture and nature, and humans and non-humans, such as fish, water, rice, camellia trees, stones and deities (Ishimure 2006: 66).

"The 'Shiranui' (lit. unknown fires on the sea) was bordered by camellia trees in the winter, spring and early summer, which gave the sea more life. Many wells situated in the marginal land of the sea were indispensable to the fishers. They cooked 'fish without salt' (fresh fish) with fresh water to satisfy their tongue. In these living things as such was the holy relationship between humans and fish... Wells in villages were built by stone walls or pebbles carefully hollowed out by Amakusa's local masons. Therefore, at these wells, village women gathered and washed rice or wheat so cautiously as to not lose even one drop of 'okome sama' (the dear precious rice). The wells are also places of deities. These communal wells in villages were almost always dug next to camellia or other evergreen plants. The trees nurtured natural springs and the natural springs nurtured trees. Many years of unknown origin were accommodated in these springs and trees. Each deity was accommodated in their own things: the deities of the wells were in the wells, the deities of the mountains were in the mountains, the deities of boats were in the boats, the deities of the rocks were in the rocks, the deities of the paddy fields were in the paddy fields, the deities of the seas or Kompira-sama ('kumbuhura' in Buddhist teachings became a guardian deity for seafarers) were in the seas, and the deities of the rivers were in the rivers... Each deity was given its own unique and endearing character... If the people liked to establish a new paddy field deity by their own field, they could simply do so by selecting a suitable stone from the field and offering local distilled spirits for the stone to put a soul in it. These human-made deities also guarded villages. Indeed, these local deities were the people themselves" (Ishimure 2006: 66; translated by the author, including explanation in parenthesis).

Deities were firmly accommodated in the local fudo of Minamata. This essential relationship between humans, spirits and nature, as well as the local people themselves, however, has been extinguished.

"These, most primitive, humble and tolerant deities were now dying. The people, uncrowned souls who never presented themselves in public and the weight of their existence, were borne from the sea of camellia and were dying out. Dying out among both the departing emigrants and the people who remained carrying the spirit of the land and sea. Displaced and shipwrecked persons, miners, manual laborers, prostitutes and refugees... Those who had been called vulgar and purified their souls by their own gore and bloodshed were now being killed" (Ishimure 2006: 67; translated by the author).

In this critical moment and place in Minamata, however, Ishimure senses slight signs of a revival of an alternative fudo relationship.

"Here, for generations, there had been no faith in the retrogressive print medias. Instead, a melting pot for the 'koto-dama' (the words of spirit) that bears the 
next generation quietly sprang forth. The transparency between sea and sky was set for this purpose. In particular, it is the heated haze of lives rising from the sea of camellia" (Ishimure 2006: 68).

Numerous academics and activists traveled to Minamata in support of those suffering from Minamata Disease. Deeply moved by their encounters with the local people and the fudo of Minamata, many such as Tsurumi (1981) or Saishu (1984) openly reflected on their modern way of thinking and writing. In the struggles revolving around Minamata Disease, Ishimure played a crucial role as a mediator between outsiders and insiders or academics, activists and local people. In the process, she expressively represented the fudo relationship in Minamata, comprised of a lifeworld of ordinary local people overlapping with their cosmology. This local fudo was dying after Minamata's historical suffering from the destruction of nature and bodies but also in the process of being revived by connections between different localities and different scales as noted later.

\section{Eiko Sugimoto's narrative on the relationship between her body and the sea}

Eiko Sugimoto (1938-2008), a victim of Minamata Disease and an activist, was a most distinguished chronicler of the disease. She was born the eldest daughter of a master fisher (amimoto) in Minamata's Modo district. From a young age, she was dearly loved and strictly trained by her father to become a leading fisher (Fujisaki 2013). However, her mother first succumbed to Minamata Disease in the late 1950s. Then her father battled the disease and died in 1969. While Eiko Sugimoto herself caught the disease before her marriage to Takeshi Sugimoto, she struggled to give birth to five sons. Intimately cooperating with her family, she desperately struggled with her disabled body as well as with discrimination and harsh harassment by neighbors because of her parents' disease and her decision to pursue justice against the Chisso company in court.

In March 1973, persons who had suffered from Minamata Disease and sought justice in court finally won their case against Chisso. After managing a small restaurant at home and growing summer oranges, Sugimoto returned to fishing, together with her husband and their children, and lived on fishing small sardines to be consumed dried or used for gardening as organic fertilizer. She says the sea has been a place for curing her disease (umi ga watashi no chiryo-ba datta chu koto deshita) (Sugimoto 2000: 142). She emphasizes Minamata's fudo as advantageous since the Minamata River carries mineralrich water to the sea to nourish the fish and shellfish. She catches fish by communicating with the sea and the fish, each of which has its own spirit. She spoke of not being able to catch fish through strategic effort but, rather, by casually encountering their spirits. It is critical that she attained this sense only after she had Minamata Disease, whereas she had just thought of herself as 'a person who catches fish' in her days of good health.

Similarly, she explained that though she suffered seriously from Minamata Disease she survived not because she chose to but, rather, because her fudo relationship with the sea allowed her to. Her father died from Minamata Disease and left her with many lessons, including the idea that, "We can never change others. Instead, we should look to change ourselves" (hitosama wa kaenaran to yade, jibun ga kawatte ike ba yoka gane) (Sugimoto 2000: 136). He gave this advice to his daughter at the time when she was being harassed by members of the neighboring fishing community. Later, these same neighbors developed the disease and, ultimately, came to understand her decision to act, leading them to apologize for their conduct. Another idea her father shared with her is that, "Minamata Disease should be 'nosari" (Minamata byo mo nosari janette omooi) (Sugimoto 2000: 146). 'Nosari' is a local term which refers to anything given to people by something beyond human intention and control. A nosari may be good or bad, such as a natural disaster or a big haul (great taking of fish).

Such discourse may sound fatalistic or resigned, but as noted above, she was a woman with strong enough will to fight against both the Chisso company and discrimination from the community, as well as her own disease as it affected her body and mind. These words, therefore, reflect her own understanding and personal discipline within her fudo relationship with Minamata constructed between the sea, fishing, farming, the community, and her own body suffering from Minamata Disease.

Sugimoto always said, "Since you must be busy when you are well, please come to Minamata when you get ill. You can soak in the sea, recover your health, and set off for home again. Please think of Minamata in this way" (Sugimoto 2000; also the author's interview with Sugimoto in 2002). Minamata-once a locale that suffered from disease and disruption of its fudo-has become a place of healing for outsiders with diminished physical and/or mental health. 


\section{The Moyai-naoshi (restoration) movement in Minamata}

Minamata represents a local case where once-stable fudo relationships became untenable after the advent of calamity. It is remarkable, however, to note that local residents have significantly reconstructed and renovated regional fudo relationships since the 1990s. Namely, the moyai-naoshi movement has done much to remedy the deep rift between society and nature, manifest as destruction and distrust. 'Moyai' is a local word meaning "a tie" or "connection," commonly used in talk of mooring ships, and 'naoshi' means restoration or, literally, "re-connecting" or "mooring again."

I highlight the major actors of the movement who were Tetsuro Yoshimoto (born 1948), a local government officer, together with Eiko Sugimoto. The movement was backed by local governments who changed their attitudes towards Minamata victims. In 1991, the then Kumamoto Prefecture Governor (and later Prime Minister in 1993-1994) Morihiro Hosokawa started the "Minamata Project for Creating Environment (Kankyo Sozo Minamata Jigyo)" with the aim of socially and environmentally restoring Minamata. The city's Mayor Masazumi Yoshii, another key person in Minamata's restoration in general and the prefectural project in particular, appointed Yoshimoto to take charge.

The first thing that Yoshimoto did was to share the experiences of Minamata victims with Minamata citizens (Yoshimoto 2008). This was an unusual decision, and one suggesting resolve, especially considering the distrust and even hatred Minamata victims felt for local government officers, known for their indifferent attitude towards Minamata Disease and the people who suffered from it.

Yoshimoto later described his first, symbolic encounter with Sugimoto as follows (the author's interview with Yoshimoto in 2002). When Yoshimoto was called to Eiko Sugimoto's house at Modo settlement, Sugimoto asked him "Who are you?" He replied "I am a mountain person" (yama no mon) as Yoshimoto was born and living in Susubaru settlement (see Figure 2). She invited him inside where she told him stories of her experiences with Minamata Disease for hours as he silently listened. When Yoshimoto was about to leave, Sugimoto said, "If a mountain person and a sea person can connect, things will surely work out alright" (yama no mon to umi no mon ga tsunagareba nantoka naru). Her statement surely represents the dynamic relationship of regional fudo and the value of (re)connection of different local fudo.

As noted earlier, Minamata consists of a variety of local areas with different fudo such as mountain vil- lages, agricultural villages, townships and coastal fishing villages. Each place actually knows little about the other. Yoshimoto said that a majority of Minamata people, himself included, did not know about Minamata Disease because many prefer not to know. The restoration of Minamata commenced under a perception that Minamata was not uniform but rather a heterogeneous collection of localities, and this internal variation and interrelationship composes the regional fudo. This holds true for local environmental conservation of the Minamata sea, as well as the social reconstruction of the society.

The project allowed Yoshimoto and others to reconstruct not only a physical environment but also a rapport between localities-once starkly divided-and a relationship between society and nature within. Moyai naoshi thus means reconnecting or reuniting such divided localities based in different fudo and constructing a mutual understanding through communal alternative fudo relationships extending throughout Minamata.

Minamata is now renowned as a model city for environmental management. Many people and institutions have come to visit and learn from Minamata, even from overseas. Yoshimoto has compiled his experiences in Minamata into Zimoto-gaku (A Study on the Local), which has inspired numerous ideas for sustainable development through local initiatives (Yoshimoto 2008). Yoshimoto's popular phrase, "naimono nedari kara arumono sagashi e" (from searching for what is lacking here to finding out what is existing here) claims the basic idea of zimoto-gaku which rediscovers the value of local place and its resources.

\section{Concluding Remarks}

\section{Reviewing Minamata's fudo with gender perspective}

Ishimure and Sugimoto were (re)presenting Minamata, not in an academic or objective style but in a subjective manner associated with their own bodies and emotions. Their reflective narratives reconstruct the interactions among body and mind, nature and culture, and humans and non-humans that constitute the fudo relationship devalued and devastated by the masculine modern form of Japan at the time of high economic growth. Thus, their narratives are closely related to their gender and femininity. While it would be too simplistic and essentialistic to say that Ishimure and Sugimoto had greater sensitivity to fudo just because they were women, as many fishermen also collectively shared identical sorts of beliefs and prac- 
tices, ${ }^{9}$ more women than men appear aware of particular interrelationships between body, mind, and nature. This should be partly because fishermen are normally more concerned with their own strategies for catching fish and remaining competitive in the market. On the other hand, the narratives of Ishimure and Sugimoto represent more sympathy for and sensitivity to the marginal, the weak, and the displaced as well as the non-human. It should be noted that Sugimoto acquired such sensibilities after she acquired Minamata Disease and gave up being a "fisherman" as trained by her father. ${ }^{10}$

Sugimoto's practice of embodying the local fudo also impacted outsiders including people from other localities in Minamata such as Yoshimoto, as well as supporters and visitors from urban areas. She intentionally sought to care for herself through consciousness of the fudo relationship between herself and nature and society. In a memorial ceremony at Minamata Bay in November 1994, she spoke representing the contaminated fish buried in reclaimed land, which emotionally overlapped with the Minamata deceasd souls. Sugimoto, a sufferer of Minamata Disease and a symbol embodying the local fudo in Minamata, continued to work as a healer for visitors to Minamata who suffered poor health and spirit until she died in 2008.

The lament and resentment expressed by Ishimure in her telling of the tragedy of Minamata was spurred by the loss of her familiar local fudo in Minamata. She listened to the silence of those suffering from Minamata Disease, as well as the voices of non-humans. Her work together with the movement of Minamata Disease radically mobilized Japanese society and spurred serious reflection on social and economic progress, because it undercut the presumed positive direction of the nation of Japan itself as it underwent rapid economic growth in the 1960s and 1970s. Numerous academics and activists firmly understood the events of Minamata as neither local nor peculiar to Minamata but as of national or global concern, rooted as they were in a crisis of the interrelationship among nature and culture, body and mind, and human and non-human, that is, a crisis of the fudo relationship.

After the advent of Minamata Disease, the fudo relationships in Minamata were divided, distorted, destroyed and forcibly confronted due to the Chisso company's economic activities, widespread environmental destruction, and government inaction, locally and nationally, as well as the hostility of Minamata citizens directed at patients and fishing persons. The fudo of fishing localities was deeply harmed, not only physically but also socially.

It should be also stressed, however, that the crisis of their own fudo and their conflict and encounters with other agents-such as fellow residents of Minamata, representatives of Chisso corporation (with a head office in Tokyo), and various activists and supporters from urban areas-prompted them to be aware and foster particular practices and expressions drawing from their original fudo relationship between place, body, and nature. The local movement reconstructed and altered Minamata's regional fudo, thus recreating a place that now attracts people interested in curing themselves, coming from elsewhere in Japan, a country dominated by capitalist and neo-liberal socio-economic change.

\section{Rethinking place through a fudo perspective}

As I define it, 'place' is an assemblage of relationships, as generated by spatial proximity, such as between people, between people and things, and between things and things, as well as the space that embodies such relationships (Kumagai 2013). Thus "place" should be regarded in the context of its micro level dynamics, rather than as a static pre-existing macro level entity. Place is open and continually generated rather than merely existing. Place is socially constructed (Harvey 1993) through particular constellations of social relations that meet and weave together at various loci without particular boundaries (Massey 1993). In the case of Minamata, a new place emerged through encounters between different agents in the Minamata locality, inclusive of people and things.

Paasi (1996: 208) notes that 'place' should be "understood as an abstraction referring to the cumulative archive of personal experiences and meanings which individuals gain from different locations and landscapes during their life-history." I agree with this view of place as produced through micro level dynamics rather than as a static pre-existing macro level entity. At the same time, his view is human-centered and individualistic; it neglects consideration of interrelationships between human and non-human bodies as well as the collective memories that cling to places.

On the other hand, as noted earlier, fudo describes esteemed inclinations inherent to relationships between humans, society, and nature. It has been historically constructed by the interrelationship or interpenetration between the material and mental, objective and subjective, and body and environment, as well as human intention and natural order. Fudo changes over time but is not swiftly altered. Sometimes fudo is transformed through external forces, as was seen in the case of Chiso's interventions, that bear no relation to already-present local fudo sensibilities. Nevertheless, the myriad relations that constitute fudo also instill it with a force that is resistant 
to changes other than those gradually nurtured through engaged agents. Using the fudo perspective, we can bridge dichotomies such as human and non-human, culture and nature, and construct a more subtle and holistic sense of place and its sustainability.

In this sense, place as viewed in the context of fudo is not retreating to a waning and closed world of nostalgia but building an alternative place of resistance against the dominant mode of the production of space (Lefebvre 1974; Escobar 2008). Thus the conceptualization of fudo enables us to integrate the three different aspects of place; 1) place as generating a sense of security and belonging; 2) place as historically constructed and 3) place as a potential site of resistance against the dominant capitalist mode of production of space.

While fudo is the relationship between nature and culture, and the material and mental or spiritual, it should be the human body or corporeality that works as an intermediary between the two. This recognition conveys the essentiality of a gender perspective, because every human body is gendered and relationships between body and mind are differently presented according to gender.

Considering gender in local and regional fudo relationships highlights that the local as well as the regional consists not of pure homogeneity and unity, as often imposed by national level sentiment, but rather a diverse and dynamic reality. Each place has many different voices and narratives, and how we hear those voices as well as how we listen to their silence is a matter for interrogation for fieldworkers seeking local and gender sensitivity.

\section{Notes}

1. While Harvey's critique of aesthetic postmodern urban space (Harvey 1989) brought the second aspect of place to the fore, he has recently signaled his sympathy for the first and third. Referring to Whitehead's conceptualization, Harvey regards "place" as entities or "permanences" that achieve relative stability for a time in their bounding and in the internal ordering of processes (Harvey 2009: 190). Harvey (2012) also noticed the social practice of "commoning" and asserts that environments treated as commons should be both collective and non-commodified. Harvey states that, "here lies one of the key spaces of hope for the construction of an alternative kind of globalization and a vibrant anti-commodification politics" (Harvey 2012: 112).

2. While Escobar illustrates the local models of nature and consciously presents a heterogeneous picture of the black community incorporating the voices of female and male activists, he nevertheless incorporates a detached narrative, together with illustrations and schemes by NGOs not fully mentioning about the local people's bodily experiences and their differences based on gender.

3. Katsue Misawa (1885-1937) is another leading and non-academic Japanese geographer who widely and practically discussed fudo. His idea of fudo is locally-based and field-oriented, and has greatly inspired physical geography. He has contributed extensively to geographical education and practices in regional development in the Shinshu region of central Japan (Misawa 2009).

4. To give one example, Watsuji presents that "feeling cold" does not refer to one's passive experience of a detached environment with low external temperature but rather expresses one's active inclination or orientation towards the coldness of the air (Watsuji 1963: 12). In other words, an individual feels their existence in the air in this relational form. In addition, individuals commonly share such feelings of coldness collectively - as a group relating to their milieu. Therefore, it is not only "I" that establishes a relationship with the air but "we."

5. When he describes a quality of ' $m u$-kando-sei' (lack of emotionality) among Chinese people (Watsuji 1963: 150-160), he presents it as an aspect of Chinese character that relates to their fudo, namely, the vastness of China's mainland. Here, he fails to recognize that ' $m u$-kando-sei' may have been historically constructed as a survival strategy in response to socio-political instability brought about by colonial invasions, in which Japan played a major part, rather than as an elemental result of their fudo.

6. Hanami, or the practice of appreciating cherry blossoms, is another good example of the fudo relationship as it shows the fascinating entanglement between culture and nature. Cherry trees originating from the mountainside were introduced for hanami to areas of human habitation more than a thousand years ago in the Nara era and, later in the Edo era, a new species with flowers that last only a week was developed and became popular in Japan. Hanami is a vital seasonal event for many Japanese people, and careful attention must be paid to when one should go since blossoms emerge at varying times each year in accordance with the climate. Japanese people generally go to hanami together with family, close friends or colleagues from work, and this enhances sociability. Thus, hanami unites nature, culture and the social in Japan (Berque 1988: 20-21).

7. A great number of books concerning Minamata Disease and its social impact have been published in Japanese by researchers such as Harada (1972, 1985), Irokawa (1995a, 1995b), Miyamoto (1977), and Tsurumi, as well as patients of Minamata Disease such as Ogata $(1996,2001)$. It should be stressed that the suffering caused by Minamata Disease poses fundamental questions pertaining to the social responsibility of academia regarding social issues and the relationship between nature, humans and society. George (2001) gives a distinguished view of this in several interviews, focusing on the Minamata movement as a site for new potential in Japan's postwar democracy based on popular thought and action.

8. The following recollections are an example of her descriptions of the inseparable relationships and interactions between body and mind, nature and culture, and humans and non-humans in Minamata over the course of its transformation.

The sea in which the poison sank was beautiful as she dreamed of the quietude of an ancient time of fishers on her surface... I walked down to the sea and felt waves on my toes when a depressed feeling bore down on me. I went up on the rocks barefoot. Smelling the fragrant flow of the wind tinged with the slight scent of salt, I leapt from rock to rock. The winter wind of the Shiranui Sea passed through my hair like gentle bubbles. At this time, the sea smelled stronger. It was the smell of the ancestral mothers whom I knew before my birth and the smell of their skin and the smell of their livelihood... Gazing closely I found not waterfowls but a torn piece of a plastic bag dried among the chips of wood and straw that made up the beach of the Shiranui Sea... This small inland sea in Japan, not fanciful, and surely not the only place where such plastic drifts ashore. It was awful to see the surfacing of such bubbles in the sea, produced as they were by that twisted alchemy that never 
did disappear. These were one of the first products of the Chisso factory of Minamata (Ishimure 2006: 63-64; translated by the author).

9. Otsuki (2010), referring her intensive fieldwork with fishers at Biwa lake in Japan, highlighted a similar fudo relationship between people and nature. While they depend on a cash economy of selling fish, they recognized that they could subsist through fishing alone and tended not to resist the unpredictability of nature.

10. Such thought is distinctly represented by Masato Ogata, one of the most prominent Minamata sufferers and activists. In his essay titled "Chisso is me," he radically reflected that Chisso embodied the modern material and institutionalized civilization and his confrontation with the company itself enhanced this scheme. Alternatively, he presented the cosmology of symbiosis among humans, fish and other creatures, as well as non-humans such as the seas and mountains. Eco-feminism (Merchant 1980; Shiva 1988) should be closely related to this type of discussion.

\section{References}

Berque, A. 1985. Kukan no nihon bunka (Japanese culture of space). Japanese translation by S. Miyahara, Tokyo: Chikuma Shobo. (J). Berque, A. 1982. Vivre lespace au Japan. Paris: Presses universitaire de France.

Berque, A. 1988. Fudo no nihon: Shizen to bunka no tsutai (Japan as milieu: Traject between nature and culture) Japanese translation by K. Shinoda, Tokyo: Chikuma Shobo. (J). Berque, A. 1986. Le sauvage et l'artifice. Les Japanais devant la nature. Paris: Gallimard.

Cresswell, T. 2004. Place: A short introduction. Oxford: Blackwell Publishing.

Escobar, A. 1995. Encountering development: The making and unmaking of the Third World. Princeton: Princeton University Press.

Escobar, A. 2008. Territories of difference: Place, movements, life, redes. Durham: Duke University Press.

Fujisaki, D. 2013. Nosari: Minamata ryoshi Sugimotoke no kioku yori. (Nosari: From a memory of Sugimoto family, fisherpersons in Minamata). Tokyo: Shin-Nihon Shuppansha. (J)

George, T. S. 2001. Minamata: Pollution and the struggle for democracy in postwar Japan. Cambridge: Harvard University Press.

Harada, M. 1972. Minamata byo (Minamata disease). Tokyo: Iwanami Shoten. (J)

Harada, M. 1985. Minamata-byo wa owatte Inai (Minamata disease has never been ended). Tokyo: Iwanami Shoten. (J)

Haraway, D. J. 1991. Simians, cyborgs, and women: The reinvention of nature. London: Free Association Books.

Harvey, D. 1989. The condition of postmodernity. Oxford: Basil Blackwell.

Harvey, D. 1993. From space to place and back again: Reflections on the condition of postmodernity. In Mapping the futures: Local cultures, global change. ed. J. Bird, B. Curtis, T. Putnam, G. Robertson and L. Tickner, 3-29. London: Routledge.

Harvey, D. 2009. Cosmopolitanism and the geographies of freedom. New York: Columbia University Press.

Harvey, D. 2012. Rebel cities: From the right to the city to the urban revolution. London: Verso.

Irokawa, D. 1995a. Kogai toshi Minamata ni okeru ningen to shi- zen no kyosei no mondai (On symbiosis of human being and nature in Minamata, a polluted city: Restoration of polluted sea and the current condition of victims: Note). Tokyo Keidai Gakkaishi 90: 159-173. (J)

Irokawa, D. ed. 1995b. Minamata no keiji: Shiranui Kai sogo chosa hokoku (Revelation from Minamata: A report of comprehensive research on shiranui-sea) Parts 1 \& 2. Tokyo: Chikuma Shobo. (J)

Ishimure, M. 1969. Kugai-Jyodo: Waga Minamata-byo. (KugaiJyodo: Our Minamata disease). Tokyo: Kodansha. (J) Translated by L. Monnet 1990. Paradise in the sea of sorrow: Our Minamata disease. Kyoto: Yamaguchi Pub. House.

Ishimure, M. 1974. Ten no uo: Zoku Kugai-Jyodo (Fish in the heaven: Second series of Kugai-Jyodo). Tokyo: Kodansha. (J)

Ishimure, M. 1976. Tsubaki no umi no ki (A story of the sea of camellias). Tokyo: Asahi Shimbunsha. (J) Translated by L. Monnet 1983. Story of the sea of camellias. Kyoto: Yamaguchi Pub. House.

Ishimure, M. 2006. Kugai-Jyodo dainibu: Kamigami no mura (Kugai-Jyodo Part 2: The deity's village). Tokyo: Fujiwara Shoten. (J)

Kumagai, K. 2013. Rethinking "place": Notes for a regional geography that transcends othering. Annals of Ochanomizu Geographical Society 5: 1-10. (J)

Lefebvre, H. 1974. La Production de lespace. Translated by H. Saito 2000. Kukan no seisan (The production of space). Tokyo: Aoki Shoten.

Longhurst, R. 2001. Bodies: Exploring fluid boundaries. New York: Routledge.

Massey, D. 1991. Flexible sexism. Environment and Planning. D, Society and Space 9: 31-57.

Massey, D. 1993. Power-geometry and a progressive sense of place. In Mapping the futures: Local cultures, global change, ed. J. Bird, 59-69. London: Routledge.

Massey, D. 2005. For space. London: Sage publications.

Merchant, C. 1980. The death of nature: Women, ecology and the scientific revolution. Munchen: Harper \& Row.

Misawa, K. 2009. Fudo no hakken to sozo (Discovery and creation of fudo). Collected works of Misawa Katsue. 4 volumes. Tokyo: Nousanson Bunka Kyokai. (J)

Monnet, L. 1990. Paradise in the sea of sorrow: Our Minamata disease. Kyoto: Yamaguchi Pub. House.

Miyamoto, K. 1977. Kogai toshi Minamata no saisei (Regeneration of Minamata, the city of environmental pollution). Tokyo: Chikuma Shobo. (J)

Nomoto, K. 2006. Kami to shizen no keikanron (An essay on landscape of deity and nature: Reading worship landscape). Tokyo: Kodansha. (J)

Ogata, M. 1996. Tokoyo no fune o kogite: Minamata-byo shishi (Rowing a boat for the eternal world: A private history of Minamata disease). Yokohama: Seori Shobo. (J)

Ogata, M. 2001. Chisso wa watashi deatta (Chisso was myself). Fukuoka: Ashi Shobo. (J)

Onjo, A. 1998. Meaning and power concerning 'place.' In Kukan kara basho e: Chirigakuteki sozoryoku no tankyu (From space to place: Exploration of geographical imaginations), ed. N. Oshiro, and M. Arayama, 226-236. Kokon Shoin. (J)

Otsuki, E. 2010. Fudo ni Ikiru, basho ni ikiru: Chiiki no henyo to 
saihensei ni kansuru chirigakuteki kenkyu (Living in fudo, living in places: A geographical study on regional transformation and reconstruction). Kyoto: Nakanishiya Shuppan. (J)

Paasi, A. 1996. Territories, boundaries and consciousness: The changing geographies of the Finnish-Russian border. New York: John Wiley \& Sons.

Relph, E. 1976. Place and placelessness. London: Sage publications.

Rose, G. 1993. Feminism and geography: The limits of geographical knowledge. Cambridge: Polity Press.

Saishu, S. 1984. Sei aru mono wa mina kono umi ni somari (All the living things are dying in this sea). Tokyo: Shinyosha. (J)

Shiva, V. 1988. Staying alive: Women, ecology and survival in India. Berkley: North Atlantic Books.

Simonsen, K. 2009. Body. In The Dictionary of human geography. 5th Edition, ed. D. Gregory, R. Johnston, G. Pratt, M. J. Watts and S. Whatmore, 50-52. Chichester: Wiley-Blackwell.

Sugimoto, E. 2000. Minamata no umi ni ikiru (Living in the sea of Minamata). In Shogen Minamata-byo (Testimonies: Minamata disease), ed. A. Kurihara, 129-146. Tokyo: Iwanami Shoten. (J)

Terada, T. 1935. Nipponjin no shizenkan (Japanese view on nature). Toyo Shicho 7: 1-32. (J)

Tuan, Y. 1974. Topophilia: A study of environmental perception, attitudes, and values. Englewood Cliffs, NJ: Prentice-Hall.

Tuan, Y. 1977. Space and place. London: Edward Arnold.

Tsurumi, K. 1981. Minakata Kumagusu. Tokyo: Kodansha. (J)

Ueda, M. 2012. Shi o mitsumete ikiru: Nipponjin no shizenkan to shiseikan (Living with a gaze of death: Japanese view on nature and death). Tokyo: Kadokawa Shoten. (J)

Watsuji, T. 1963 [1935]. Fudo: Ningengaku-teki kosatsu (Milieu: Consideration from human studies). Tokyo: Iwanami Shoten. (J)

Yoshimoto, T. 2008. Zimotogaku o hajimeyo (Let's start a study of the local). Tokyo: Iwanami Shoten. (J)

(J) written in Japanese 